\title{
O papel do preceptor na formação profissional em serviço de saúde
}

\author{
Andréa Clemente Palmier*; Hindyara Brione Teixeira**; Cléris Blanco de Souza***; João Henrique \\ Lara do Amaral****; Marcos Azeredo Furquim Werneck****; Renata de Castro Martins*
}

* Doutora em Odontologia, área de concentração Saúde Coletiva, Professora associada, Departamento de Odontologia Social e Preventiva da FOUFMG

** Cirurgiã-dentista

*** Enfermeira, gerente de Unidade Básica de Saúde da Prefeitura Municipal de Belo Horizonte

**** Doutor em Odontologia, área de concentração Odontologia Social, Professor titular, Departamento de Odontologia Social e Preventiva da FOUFMG

Recebido: 12/07/2021. Aprovado: 22/11/2021.

\begin{abstract}
RESUMO
O estudo objetivou avaliar o papel do preceptor na formação do estudante de Odontologia na disciplina "Estágio Supervisionado em Odontologia" da Faculdade de Odontologia da UFMG. Foi utilizado um questionário com questões abertas e fechadas sobre as experiências e impressões dos estudantes, professores e preceptores de seis campos de estágio localizados em Belo Horizonte. Onze estudantes, dez preceptores e quatro professores participaram deste estudo. Todos os alunos e professores e $50 \%$ dos preceptores consideram que a preceptoria faz parte das atribuições do profissional de saúde. A maioria dos atores afirmou que o profissional de saúde se sente motivado e preparado para atuar como preceptor. Todos os atores consideraram importante a participação do estudante em estágios em serviços de saúde durante a formação profissional e afirmaram que o preceptor tem conhecimento sobre os objetivos da disciplina. Apenas $20 \%$ dos preceptores afirmaram que já participaram de curso de capacitação de preceptoria e $80 \%$ manifestaram interesse em participar. A percepção dos participantes sobre o papel do preceptor na formação do profissional de saúde foi positiva. Alguns preceptores não têm consciência de que a preceptoria faz parte de sua atribuição como profissional da saúde. São necessárias ações que busquem capacitar e conscientizar os preceptores do seu papel na formação dos futuros profissionais de saúde.

Descritores: Preceptoria. Sistema Único de Saúde. Atenção à Saúde. Recursos Humanos em Odontologia.
\end{abstract}

\section{INTRODUÇÃO}

O Sistema Único de Saúde (SUS) deve ordenar a formação de recursos humanos na área da saúde ${ }^{1}$. O cirurgião-dentista deve ser capacitado ao exercício de atividades referentes à saúde bucal da população, pautado em princípios éticos, legais e na compreensão da realidade social, cultural e econômica do seu meio, dirigindo sua atuação para a transformação da realidade em benefício da sociedade. Neste contexto, a formação do 
cirurgião-dentista deve contemplar o sistema de saúde vigente no país, a atenção integral da saúde num sistema regionalizado, com referência e contrarreferência e o trabalho em equipe. Segundo as Diretrizes Curriculares Nacionais (DCN), a formação deve garantir o desenvolvimento de estágios curriculares em unidades de saúde do SUS de forma articulada e com complexidade crescente ao longo do processo de formação, sob supervisão docente e de profissional do serviço que recebe o aluno $^{2}$. Para atender ao que determina a Constituição e as DCN é necessário que estejam implicados no processo formativo dos profissionais de saúde não só a instituição de ensino, representada pelo próprio estudante e pelo professor e o SUS presente na pessoa do trabalhador/preceptor, mas também a gestão do sistema e o controle social. De acordo com Forte et al. $(2015)^{3}$ a inserção do preceptor no processo de formação de cirurgiões-dentistas traz uma nova perspectiva na abordagem do processo ensinoaprendizagem. Da Luz e Toassi $(2016)^{4}$ afirmam que os estudantes reconhecem o preceptor como um agente de integração entre eles e a equipe de saúde multiprofissional que atua nas Unidades de Saúde. O preceptor recebe os estudantes, e apresenta-lhes à equipe e ao serviço. Neste cenário fica evidente que o preceptor/trabalhador do sistema produz saberes, práticas e vivências fundamentais para a formação do aluno como proposta pelas DCN. É importante que o preceptor se envolva de forma aberta, generosa, crítica e consciente com todo o processo de estágio/vivência do aluno.

Considerando a relevância do papel dos preceptores na formação dos estudantes da área da saúde, foi realizado um estudo avaliando a opinião dos profissionais do serviço de várias áreas da saúde sobre a atividade de preceptoria, como parte de um projeto mais amplo de avaliação de integração docente-assistencial. A maior parte dos profissionais mostrou interesse em desempenhar o papel de preceptor e concordou que a preceptoria possui um impacto importante na formação do aluno. Entretanto, muitos profissionais reconheceram como dificuldades para o desenvolvimento das atividades de preceptoria problemas com infraestrutura e, em menor escala, com recursos humanos. Os profissionais com vínculo em Instituições de Ensino Superior foram os que responderam, com maior frequência, que gostariam de desempenhar o papel de preceptoria, possivelmente por se sentirem mais seguros por já desenvolverem atividades de ensino. A maioria dos profissionais relatou não encontrar apoio institucional ou oferecimento de oportunidades para acesso a cursos de formação especializada em saúde da família, saúde coletiva ou mesmo para exercício de uma clínica de cunho generalista. Os pontos positivos mais apontados pelos preceptores foram a possibilidade de seu próprio desenvolvimento pessoal e a melhoria do atendimento ${ }^{5}$.

As parcerias entre Instituições de Ensino Superior (IES) e Secretarias Municipais de Saúde (SMS) precisam ser revistas para atender aos anseios dos docentes, discentes, profissionais do serviço, gestores e comunidade. Nem sempre o que as IES entendem como necessidades de saúde da população significa, de fato, o que ela deseja; e quanto mais os atores se envolverem com as decisões, discutindo-as coletivamente, mais efetivo se tornará o benefício para todos. O conhecimento das DCN, dos objetivos do curso e do perfil do egresso de cada IES que estabelece parcerias com a unidade de saúde também precisa ser discutido com o profissional para que este possa compreender qual o seu papel e sua responsabilidade na formação do estudante ${ }^{5}$.

A Faculdade de Odontologia da Universidade Federal de Minas Gerais (FAOUFMG) participa dos esforços do Programa de Reestruturação e Expansão das Universidades Federais (REUNI) com uma expansão de $20 \%$ de 
suas vagas para o Curso de Graduação em Odontologia. A disciplina Estágio Supervisionado em Odontologia acontece no último período do curso com carga horária de 300 horas podendo ser realizada em Centros de Saúde de Belo Horizonte (Internato Metropolitano desde 1992) ou em cidades do interior de Minas Gerais (Internato Rural desde 2000). O aluno trabalha na atenção à saúde sob a supervisão do professor e dos profissionais do serviço (cirurgião-dentista, Coordenador de Saúde Bucal, Secretário de Saúde). O professor exerce uma supervisão à distância e presencial quinzenal. E o preceptor uma supervisão presencial e contínua. Tendo em vista que as DCN sugerem que a formação do aluno no campo da saúde deve ser baseada em três eixos orientadores (trabalho em equipe; apropriação do sistema de saúde vigente; integralidade no cuidado à saúde) é importante conhecer as dificuldades encontradas pelos profissionais do serviço no que diz respeito aos três eixos para atuar como preceptores. $\mathrm{Na}$ recente mudança da matriz curricular do Curso de Odontologia da UFMG as oportunidades de formação em serviço tiveram uma ampliação significativa para além do último período de formação do curso. Outros períodos têm contato com os serviços de saúde, seus trabalhadores, gestores e comunidade. Portanto, um projeto que visa intervir no processo ensinoaprendizagem que acontece na rede de serviços, pode contribuir positivamente para a melhoria da formação do futuro profissional. O presente estudo tem por objetivo avaliar o papel do preceptor na formação profissional do estudante de Odontologia no serviço de saúde bucal.

\section{METODOLOGIA}

Trata-se de estudo transversal, de abordagem quantitativa e qualitativa por categorização foi desenvolvido com os profissionais de saúde bucal de Belo Horizonte que atuam como preceptores dos estudantes de Odontologia na disciplina "Estágio
Supervisionado em Odontologia" da Faculdade de Odontologia da Universidade Federal de Minas Gerais (FAO-UFMG); bem como os estudantes e professores.

Atualmente, a disciplina "Estágio Supervisionado em Odontologia" atua em 06 campos de estágio em Belo Horizonte localizados na regional Norte (Centros de Saúde Amélia Rocha, Jardim Guanabara, Novo Aarão Reis, Primeiro de Maio, Providência e São Tomaz). A amostra foi calculada de forma a contemplar 1 profissional de saúde bucal atuando como preceptor, dois estudantes cursando a disciplina nesses campos de estágio e um professor supervisor em cada Centro de Saúde.

Este projeto foi submetido ao Comitê de Ética em Pesquisa da UFMG (CAAE 44100415.3.0000.5149) e aprovado sob o parecer $\mathrm{n}^{\circ} 1.083 .556$.

Para a coleta de dados foi elaborado um questionário, testado em estudo piloto com preceptores, estudantes e professores que não participaram desse estudo, abordando questões abertas e fechadas sobre as experiências e impressões dos preceptores, estudantes e professores que atuam nos campos de estágios, considerando aspectos relevantes do papel do preceptor na formação do profissional em saúde em Odontologia.

Os questionários foram entregues aos participantes pelos pesquisadores nos campos de estágio e recolhidos no mesmo dia.

Uma análise descritiva dos dados foi realizada e operacionalizada com auxílio do programa estatístico Statistical Package for Social Sciences - SPSS versão 18.0 (IBM, Armonk, NY, EUA).

Para a análise qualitativa, as questões abertas foram agrupadas em categorias.

\section{RESULTADOS}

Participaram do estudo 11 estudantes, 10 
preceptores e 4 professores distribuídos pelos seis Centros de Saúde (tabela 1). Dois professores atuavam em dois Centros de Saúde diferentes. Os questionários foram aplicados aos 3 atores (estudantes, professores e preceptores), sendo que a maioria das perguntas eram as mesmas.

$\mathrm{Na}$ avaliação dos atores, todos os alunos e professores $(100 \%)$ consideram que a preceptoria faz parte das atribuições do profissional de saúde. Por outro lado, 5 (50\%) preceptores discordaram (tabela 2) justificando que não recebem gratificação para exercer o cargo de preceptor que a preceptoria deveria ser opcional.

Em relação à motivação e preparo do profissional de saúde para atuar como preceptor, a maioria das respostas foi positiva (tabelas 3 e 4). Apenas um preceptor respondeu negativamente, justificando falta de apoio de recurso de pessoal e de técnicos. Já entre os estudantes dois disseram que os seus respectivos preceptores não estavam motivados, explicando que os dentistas não tinham tempo para a preceptoria. Quanto ao preparo para a função de preceptoria, dois dentistas disseram que não se sentiam preparados. Um justificou que era a primeira experiência e o outro disse não saber até onde vai o seu papel. No entanto, mesmo os que relataram se sentir preparados, comentaram que seria importante que houvesse capacitação de preceptoria. Apenas 2 (20\%) preceptores afirmaram que já participaram de curso de capacitação de preceptoria e quando perguntados sobre o interesse em participar, 8 (80\%) manifestaram interesse.

Quando questionados sobre quais competências são importantes para exercer o papel de preceptoria, dentre os preceptores as respostas foram: Paciência, habilidade para ensinar, conhecimento técnico-prático, compromisso, capacidade de ouvir, percepção das potencialidades e limitações dos alunos. Entre os alunos as competências mais apontadas foram: Conhecimento teórico e clínico, tempo, interesse, paciência, facilidade em transmitir o conhecimento. Os professores consideraram que o conhecimento teórico e sobre o SUS, saber trabalhar em equipe as competências mais importantes para o dentista exercer o papel de preceptoria.

Considerando os aspectos que os participantes consideravam mais importantes sobre as atividades de preceptoria, os estudantes elencaram o trabalho em equipe $(n=9 ; 81 \%)$ e a relação com a comunidade $(n=6 ; 54 \%)$. Para os professores a organização do serviço e a relação com a gestão $(n=3 ; 75 \%)$ foram os aspectos mais importantes, enquanto os preceptores valorizaram mais os aspectos assistenciais e a organização do serviço $(n=7 ; 70 \%)$ (tabela 5 e gráfico 1$)$.

Tabela 1. Composição da amostra, distribuição de estudantes, professores e preceptores por Centro de Saúde

\begin{tabular}{lccc}
\hline Centro de Saúde & Estudantes & Professores & Preceptores \\
\hline $1^{\mathbf{0}}$ de maio & 1 & Professor 1 & - \\
Novo Aarão Reis & 2 & Professor 1 & 2 \\
Amélia Rocha & 2 & Professor 2 & 2 \\
São Tomaz & 2 & Professor 3 & 1 \\
Jardim Guanabara & 2 & Professor 4 & 2 \\
Providência & 2 & Professor 4 & 3 \\
\hline Total & $\mathbf{1 1}$ & $\mathbf{4}$ & $\mathbf{1 0}$ \\
\hline
\end{tabular}


Tabela 2. Percepção dos estudantes, professores e preceptores em relação à preceptoria ser uma atribuição do profissional de saúde

\begin{tabular}{lccccc}
\hline Respondente & n & Sim & \% & n & Nã \\
\hline Estudante & 10 & 100,0 & - & - \\
Professor & 4 & 100,0 & - & - \\
Preceptor & 5 & 50,0 & 5 & 50,0 \\
\hline
\end{tabular}

Tabela 3. Percepção dos estudantes, professores e preceptores em relação à motivação do profissional de saúde para atuar como preceptor

\begin{tabular}{lccccc}
\hline Respondente & n & Sim & N & n & \% \\
& n & \% & 18,0 \\
Estudante & 9 & 82,0 & 2 & - \\
Professor & 4 & 100,0 & - & 10,0 \\
Preceptor & 9 & 90,0 & 1 & \\
\hline
\end{tabular}

Tabela 4. Percepção dos estudantes, professores e preceptores em relação à preparação do profissional de saúde para atuar como preceptor

\begin{tabular}{lccccc}
\hline Respondente & n & Sim & n & Não & \% \\
\hline Estudante & 11 & & 100,0 & - & - \\
Professor & 3 & & 75,0 & 1 & 25,0 \\
Preceptor & 8 & & 80,0 & 2 & 20,0 \\
\hline
\end{tabular}

Tabela 5. Percepção dos estudantes, professores e preceptores em relação a aspectos mais importantes das atividades de preceptoria

\begin{tabular}{|c|c|c|c|c|c|c|c|c|c|}
\hline \multirow{2}{*}{ Variável } & \multicolumn{3}{|c|}{ Estudante n (\%) } & \multicolumn{3}{|c|}{ Professor n $(\%)$} & \multicolumn{3}{|c|}{ Preceptor n (\%) } \\
\hline & 3 & 2 & 1 & 3 & 2 & 1 & 3 & 2 & $\mathbf{1}$ \\
\hline $\begin{array}{l}\text { Aspectos } \\
\text { assistenciais }\end{array}$ & - & $5(45,0)$ & $6(54,0)$ & $1(25,0)$ & $1(25,0)$ & $2(50,0)$ & $7(70,0)$ & - & $3(30,0)$ \\
\hline $\begin{array}{l}\text { Organização do } \\
\text { serviço }\end{array}$ & $4(36,0)$ & $1(10,0)$ & $6(54,0)$ & $3(75,0)$ & - & $1(25,0)$ & $7(70,0)$ & $2(20,0)$ & $1(10,0$ \\
\hline $\begin{array}{l}\text { Relação } \\
\text { comunidade }\end{array}$ & $6(54,0)$ & $1(10,0)$ & $4(36,0)$ & $2(50,0)$ & $1(25,0)$ & $1(25,0)$ & $2(20,0)$ & $2(20,0)$ & $6(60,0)$ \\
\hline Relação gestão & $3(27,0)$ & $4(36,0)$ & $4(36,0)$ & $3(75,0)$ & - & $1(25,0)$ & $1(10,0)$ & - & $9(90,0)$ \\
\hline Trabalho em equipe & $9(81,0)$ & - & $2(19,0)$ & $2(50,0)$ & $1(25,0)$ & $1(25,0)$ & $3(30,0)$ & $6(60,0)$ & $1(10,0)$ \\
\hline
\end{tabular}




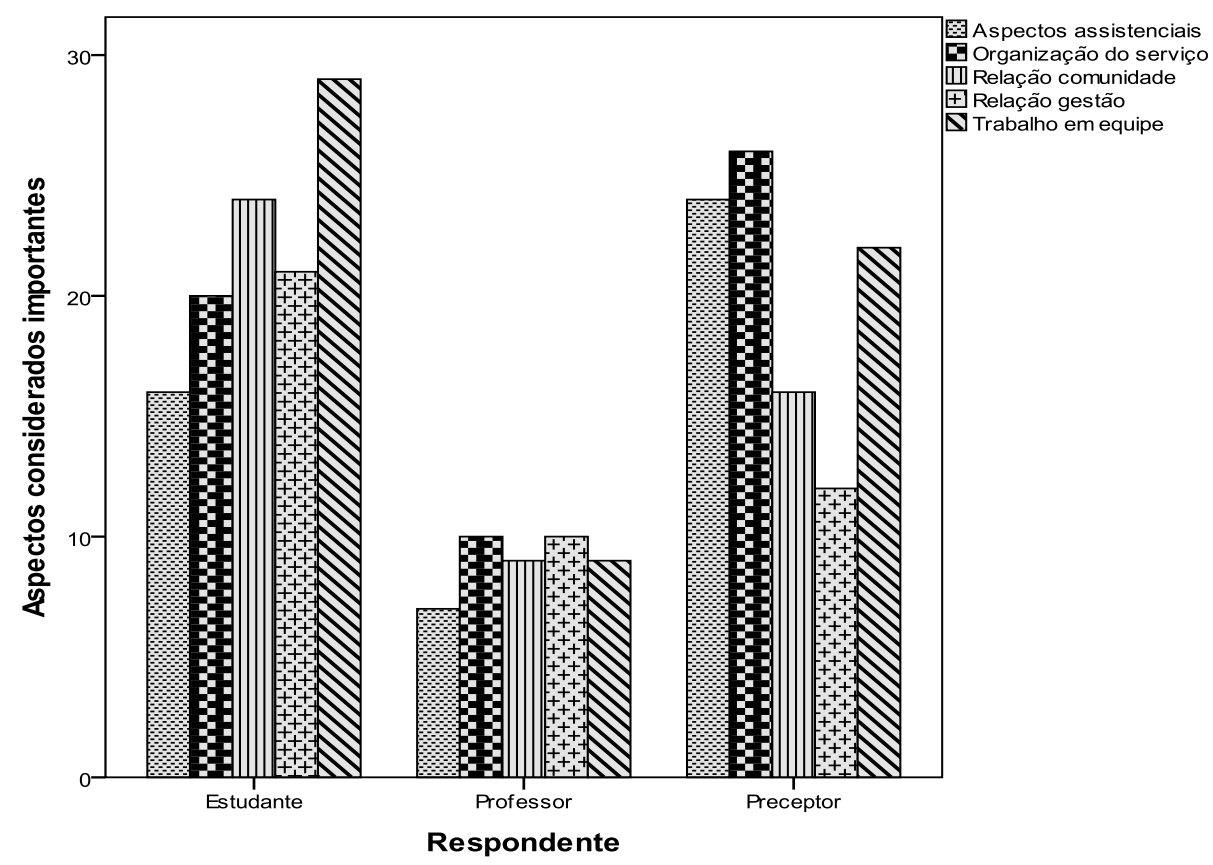

Gráfico 1. Percepção dos estudantes, professores e preceptores em relação a aspectos mais importantes das atividades de preceptoria

Os estudantes avaliaram o papel do preceptor como muito importante, pois os preceptores mostram uma nova rotina, uma nova visão da odontologia, além de haver uma troca de conhecimento e proporcionar maior segurança aos alunos em relação ao atendimento odontológico. Para os professores, o papel do preceptor é importante, tendo em vista que o preceptor é o modelo de profissional do SUS para o aluno, e a qualidade da relação com o estudante influenciará o quanto o aluno compreenderá e aprenderá sobre a prática ali realizada. $\mathrm{Na}$ visão dos preceptores, o papel que eles exercem é importante, pois auxiliam os estudantes a melhorar as habilidades, a conhecer o SUS, e a aumentar a experiência clínica.

Todos os atores (100\%) consideraram importante o estudante participar de estágios em serviços de saúde durante a sua formação profissional e foram unânimes em afirmar que o preceptor tem conhecimento sobre os objetivos da disciplina Estágio Supervisionado em Odontologia.

Todos os professores e a maioria dos preceptores $(90 \%)$ e estudantes $(72,72 \%)$ relataram que o planejamento é feito de forma participativa. Um preceptor (10\%) não respondeu a esta pergunta e três alunos $(27,28 \%)$ responderam negativamente, justificando que a reunião aconteceu só com o professor, ou que o preceptor já tinha conhecimento sobre as atividades que seriam desenvolvidas e, dessa forma, não havia necessidade. Ao avaliarem as atividades planejadas, todos os atores (100\%) consideram que estão de acordo com as necessidades da unidade de saúde e de saúde da população.

As relações estabelecidas entre os atores (estudante $\mathrm{x}$ preceptor, estudante $\mathrm{x}$ professor, professor $\mathrm{x}$ preceptor) foram avaliadas como boa por todos os atores envolvidos (100\%). O ambiente de trabalho foi considerado adequado para o desenvolvimento do estágio pela maioria dos participantes. Apenas um preceptor não respondeu a esta pergunta (10\%) e um aluno (9\%) não julgou o ambiente de trabalho adequado, explicando que não tinham cadeiras odontológicas suficientes para todos os profissionais e estudantes. A infraestrutura 
para realizar as atividades de estágio foi avaliada adequada por todos os estudantes e professores e por $60 \%$ dos preceptores. Um preceptor (10\%) não respondeu a esta pergunta. Dentre os que responderam negativamente, as justificativas foram à limitação estrutural, a falta de materiais e os equipamentos com defeito.

Em relação às dificuldades para exercer a preceptoria, os dentistas apontaram a falta de tempo como o principal fator, além de falta de recursos e de estrutura, alunos desinteressados e falta de objetividade da universidade. Para os estudantes, a falta de tempo também dificulta a preceptoria, mas também apontaram a dificuldade em transmitir conhecimento por parte do preceptor, e falta de habilidade do preceptor para coordenar um estágio. Para os professores, a dificuldade que o preceptor encontra está na agenda cheia, em trabalhar em um centro de saúde despreparado para o estágio, e a dificuldade em conhecer os eventos de interferência no aprendizado e suas atividades em situações reais de trabalho.

Considerando as facilidades encontradas para exercer a função de preceptoria, os dentistas apontaram a boa relação com os alunos e a colaboração da equipe como principais fatores que facilitam a função de preceptor. Para os estudantes, os pontos mais importantes são: experiência sobre o serviço, conhecimento teórico-clínico e boas relações interpessoais.

$\mathrm{Na}$ visão dos professores, os fatores que mais facilitam a preceptoria foram: o prazer que o dentista tem em acrescentar a sua rotina um conhecimento novo, o comprometimento com a unidade básica de saúde e com o estágio supervisionado.

Quando solicitadas sugestões para melhorar a integração ensino/serviço e o papel de preceptor, os dentistas sugeriram cursos e capacitações, recebimento de gratificações por exercer a atividade de preceptoria, aumentar o período de estágio supervisionado para os alunos, melhorar a infraestrutura do centro de saúde, uma maior presença do professor, mais objetividade da faculdade. Para os estudantes, o preceptor deveria ser remunerado, para que houvesse, assim, estímulo pela atividade, o estágio deveria durar mais tempo e que houvesse um maior diálogo entre o centro de saúde e a universidade. Dentre os professores apenas um apontou a necessidade de um processo de educação permanente.

\section{DISCUSSÃO}

De acordo com a lei $8080 / 90^{6}$, a ordenação da formação de recursos humanos na área de saúde é de atribuição do SUS. Segundo as DCN, a formação do profissional de saúde deve garantir o desenvolvimento de estágios curriculares em unidades de saúde do SUS de forma articulada e com complexidade crescente ao longo do processo de formação, sob supervisão docente e de um profissional do serviço que recebe o aluno ${ }^{2,7}$. Os cirurgiões-dentistas, funcionários do serviço público de saúde, que acompanham e supervisionam o estudante nos campos de estágio são chamados de preceptores ${ }^{8}$. Sendo assim, é uma atribuição do profissional de saúde atuar como preceptor.

Apenas um estudante e um preceptor não aceitaram participar do estudo, o que reflete uma boa taxa de resposta. Era estimado que cada centro de saúde teria um preceptor, mas em alguns foram encontrados 2 e até 3 profissionais atuando na preceptoria.

Todos os alunos e professores consideraram que a preceptoria faz parte das atribuições dos profissionais do serviço. Entretanto, metade dos preceptores (50\%) considerou que não, justificando que não recebem gratificação para exercer o cargo de preceptor e que a preceptoria deveria ser opcional, sugerindo um desconhecimento da própria função de seu trabalho. Este desconhecimento dos preceptores sobre o seu papel no processo pedagógico de formação do estudante 
da área de saúde também foi evidenciado por Trajman et al. (2009) ${ }^{5}$. Um fator que pode ter contribuído para esta resposta negativa é o fato de que, em uma mesma unidade de saúde, alguns profissionais recebem incentivos financeiros para o acompanhamento de alunos por meio do Programa de Educação Tutorial (PET) e Programa de Educação Permanente (PEP), enquanto outros não.

A maioria dos participantes relatou que os preceptores se sentem motivados e preparados para atuar nesta função. Os participantes que responderam negativamente apontaram a falta de tempo como razão para a desmotivação. Quanto ao preparo para a função de preceptoria, dois dentistas disseram que não se sentiam preparados. Um justificou que era a sua primeira experiência e o outro disse não saber até onde iria o seu papel. Muitos profissionais de saúde têm interesse em desempenhar a função de preceptor, mas apontam como dificuldades para o desenvolvimento das atividades de preceptoria, dificuldades na infraestrutura (espaço e recursos inadequados) e, em menor escala, problemas de recursos humanos como despreparo e falta de tempo ${ }^{5,9}$.

Quando os preceptores foram questionados em relação às competências mais importantes para exercer a função de preceptoria, eles apontaram a paciência, a habilidade para ensinar e o conhecimento técnico-prático. Para os alunos as competências mais apontadas foram: conhecimento teórico e clínico, tempo, interesse, paciência, facilidade em transmitir o conhecimento. O conhecimento teórico e sobre o SUS e o saber trabalhar em equipe foram às características mais importantes indicadas pelos professores para que o dentista exerça bem o papel de preceptoria.

Em relação às facilidades encontradas para exercer o papel de preceptor, os dentistas destacaram o bom convívio, as boas relações interpessoais e a colaboração da equipe. Para Barreto et al. $(2011)^{10}$ a relação entre preceptor e educando é um importante instrumento para a descoberta do trabalho coletivo. Outros pontos ressaltados pelos alunos foram a experiência sobre o serviço e o conhecimento teórico-clínico. Para os professores os pontos citados são: o prazer que o dentista tem em acrescentar a sua rotina um conhecimento novo, o comprometimento com a unidade básica de saúde e com o estágio supervisionado. Sobre as dificuldades encontradas, a falta de tempo foi resposta dos três grupos. Os dentistas também apontaram a falta de recursos e de estrutura, alunos desinteressados e falta de objetividade da Universidade. Os estudantes destacaram a dificuldade em transmitir conhecimento por parte do preceptor, e a falta de habilidade do preceptor para coordenar um estágio. Para os professores, a dificuldade que o preceptor encontra está em trabalhar em um centro de saúde despreparado para o estágio.

Todos os participantes (100\%) consideraram importante o estudante participar de estágios em serviços de saúde durante a sua formação profissional. Julga-se que os estágios no SUS são oportunidades de acrescentar experiência profissional e de vida ao estudante de odontologia ${ }^{8}$. Os estudantes, de uma forma geral, valorizam o aprendizado por meio da prática no serviço, do contato com profissionais de outras áreas, da oportunidade de aperfeiçoamento técnicooperatório e demonstram sensibilização frente à realidade social ${ }^{11}$. A viabilização dos estágios é, sem dúvida, uma estratégia para formar profissionais de saúde com perfil mais adequado às diretrizes político-sanitárias, com benefício direto à população assistida pelo SUS $^{5}$.

Neste estudo, todos os participantes foram unânimes em afirmar que o preceptor conhecia os objetivos da disciplina Estágio Supervisionado em Odontologia. As IES e seus cursos na área de saúde devem ter cuidados a ponto de não impor esquemas preconcebidos que possam prejudicar a percepção da realidade ou predefinir propostas de trabalho do 
serviço, mas sim adequar às atividades demandadas pelos municípios aos objetivos da formação profissional ${ }^{7}$. O conhecimento das DCN, dos objetivos do curso e do perfil do egresso de cada IES que estabelece parcerias com a unidade de saúde também precisa ser discutido com o profissional para que este possa compreender qual o seu papel e sua responsabilidade na formação do estudante ${ }^{5}$.

Todos os atores consideraram importante o papel do preceptor. Cada grupo estudado valorizou aspectos diferentes das atividades de preceptoria. Para os professores, os aspectos mais importantes foram a organização do serviço e a relação com a gestão, provavelmente porque é por meio dessa relação que é possível planejar as atividades que serão desenvolvidas durante o estágio, e a organização do serviço é importante para permitir que as atividades sejam realizadas. Os preceptores também valorizaram a organização do serviço, o que facilitaria a orientação, e os aspectos assistenciais. Talvez, na percepção do preceptor, o estudante precise aprimorar sua habilidade clínica e por isso a importância dos aspectos assistenciais foi ressaltada por $70 \%$ deste grupo. O potencial transformador da inserção em serviço ainda é pouco explorado tendo em vista que a relação entre o trabalhador do serviço/preceptor e o processo de ensino é quase sempre restrita à orientação nos aspectos exclusivamente assistenciais e específicos do campo nuclear do saber profissional. Para Da Luz e Toassi $(2016)^{4}$ o preceptor incentiva o pensamento reflexivo, facilita ainda mais a aproximação do estudante com o trabalho realizado nas Unidades de saúde, possibilitando que o mesmo associe os conhecimentos teóricos adquiridos na universidade com a realidade na qual está inserido. Chama a atenção o fato dos estudantes não terem valorizado os aspectos assistenciais como um dos pontos mais importantes das atividades de preceptoria, ao que vai contra o trabalho de Leme et al. $(2015)^{11}$. Na visão de muitos estudantes, o estágio atrapalha o desempenho das atividades na clínica da faculdade. Este fato parece estar relacionado à ideia de que o estágio é uma atividade paralela, menos importante e não integrante do ciclo de formação. Isso pode estar associado ao fato de sua implementação se dar pelo esforço prioritário, senão isolado, das disciplinas de saúde coletiva, além de uma visão fragmentada dos alunos entre a prática privada e a pública, reforçada pela extensa carga horária da clínica intramuros.

No presente estudo, a relação com a comunidade e o trabalho em equipe foram os fatores mais valorizados pelos estudantes nas atividades de preceptoria, provavelmente por serem ações pouco desenvolvidas durante a graduação e eles terem a oportunidade de desenvolvê-las no estágio. Diversos pontos nas DCN indicam a necessidade de uma formação voltada para a multidisciplinaridade, interdisciplinaridade, multiprofissionalidade e habilidades de comunicação com a equipe ${ }^{2}$. O estágio proporciona, aos estudantes, a oportunidade de vivenciar na prática em ambientes diferentes, perceber modos de ser ou estar e de condições de vidas desiguais na relação com a comunidade.

No presente estudo todos os professores e a maioria dos preceptores (90\%) e estudantes $(72,72 \%)$ relataram que o planejamento é feito de forma participativa. Por isso, o planejamento foi considerado adequado tanto às necessidades da unidade de saúde e da população de sua área de abrangência. Isso sugere que a tentativa de aproximar as ações acadêmicas das atividades do serviço tem sido positiva nessa disciplina.

Uma questão muito importante é o relacionamento entre os atores que foi avaliado positivamente por todos eles. Sem dúvida isto cria um ambiente de trabalho propício, respeitando os saberes em uma convivência harmônica e ética. Para os estudantes é importante que o professor e preceptor sejam preparados, engajados e 
comprometidos com a proposta do estágio, pois o elo entre teoria e prática inicia-se na sala de aula e no estágio com estes dois atores, e vai se construindo no dia a dia de sua formação acadêmica e, também, ao longo dos estágios ${ }^{8}$.

Em apenas um centro de saúde a infraestrutura para o estágio não foi considerada adequada pelos preceptores, sendo que as justificativas foram à limitação estrutural, a falta de materiais e os equipamentos com defeito. De acordo com Trajman et al. (2009) ${ }^{5}$ as condições de infraestrutura precisam ser adequadas para o acolhimento do estudante. O reduzido espaço e as precárias condições físicas são apontados como pontos negativos por preceptores para o desenvolvimento dos estágios. A melhoria das condições de trabalho deve ser considerada pelas autoridades competentes para que a rede básica possa, de fato, constituir um espaço adequado de treinamento dos estudantes.

Apenas $20 \%$ dos preceptores participaram de algum curso de capacitação de preceptoria e $80 \%$ gostariam de participar. Este resultado está de acordo com Trajman et al. (2009) ${ }^{5}$. Segundo este autor, a maioria dos profissionais da rede não encontra apoio institucional ou oferta de oportunidades para acesso a cursos de formação especializada em saúde da família. Além disso, a ausência de clareza a respeito da função da preceptoria demonstra a necessidade iminente de que as universidades reconheçam e proporcionem condições para que estes profissionais se capacitem e desenvolvam habilidades técnicas e éticas para atuar em sua dupla função com segurança e competência ${ }^{5,12}$.

Após o curso de capacitação os preceptores passam do desconhecimento da função pedagógica do preceptor, da desvalorização de tal função pela instituição e por eles mesmos, para uma situação oposta em que é possível explorar as possibilidades da função de preceptoria e dos recursos educacionais.
É importante deixar claro, que o profissional precisa ser capacitado não apenas do ponto de vista da atualização profissional, mas formados também na concepção de educação permanente. Sendo assim, o curso de preceptores deve buscar evidenciar as potencialidades pedagógicas do processo de trabalho para que esses profissionais permaneçam em formação nos seus cenários de prática, utilizando os seus problemas reais como questões orientadoras da aprendizagem ${ }^{12}$.

Em relação às sugestões apresentadas pelos participantes para melhorar a integração ensino/serviço e o papel de preceptor, foram apontadas: melhoria das condições de trabalho como, melhor remuneração e capacitação dos profissionais, melhoria da infraestrutura da unidade e um maior diálogo entre o centro de saúde e a universidade. Um professor apontou a necessidade de um processo de educação permanente.

Para Warmling et al. $(2011)^{13}$ os novos percursos curriculares da graduação em odontologia devem conseguir formar perfis profissionais predominantemente generalistas, entretanto esse é um modelo de formação novo e que ainda necessita de uma concordância em torno do modo que deve ser feito para formar esses profissionais.

\section{CONSIDERAÇÕES FINAIS}

O estágio curricular nos serviços de saúde contribui tanto para a formação de profissionais que respondam adequadamente às necessidades humanitárias e de comprometimento social previstas no sistema de saúde do país, quanto para uma aproximação da academia aos serviços de saúde e da comunidade. Neste sentido, é importante conhecer o papel do preceptor no processo ensino aprendizagem e do trabalho em saúde. Este profissional produz saberes, práticas e vivências fundamentais para a formação do aluno como proposta pelas DCN. O conhecimento e as experiências destes trabalhadores envolvem 
questões sobre o cotidiano da assistência em saúde, da organização dos serviços de saúde, das relações com a comunidade e com a gestão. É necessária a valorização da prática pedagógica por eles desenvolvida e um maior empenho das IES na capacitação deles. Este estudo mostrou que, de uma forma geral, a percepção dos participantes sobre o papel do preceptor na formação do profissional de saúde foi positiva. O profissional de saúde se mostrou motivado e preparado para atuar como preceptor, apresentou conhecimento sobre os objetivos da disciplina, participou do planejamento das atividades do estágio, que estavam adequadas às necessidades da unidade de saúde e de saúde da população, estabeleceu boas relações interpessoais com alunos a professores, e desta forma, o trabalho pode ser desenvolvido dentro de um adequado ambiente de trabalho. Foi interessante observar que a maioria dos preceptores valoriza os aspectos assistenciais e a organização do serviço para desempenhar suas funções de preceptoria, e quase a metade deles considera que a infraestrutura para realizar as atividades de estágio não esteja adequada. Metade dos preceptores considera que a preceptoria não faça parte das atribuições do profissional de saúde, o que denota um desconhecimento da função pedagógica do preceptor. Isto aponta para uma falta de informação destes profissionais sobre a importância do preceptor na formação dos profissionais da saúde. Os saberes deste profissional vão além da prática clínica envolvem, também, as relações que se estabelecem dentro do processo de trabalho, vivências que são fundamentais para a formação do aluno. $\mathrm{O}$ fato de a maioria manifestar interesse em participar de cursos de capacitação mostra que pode haver uma lacuna na formação destes profissionais para exercerem sua função pedagógica. Os cursos de capacitação devem buscar evidenciar as potencialidades pedagógicas do processo de trabalho para que esses profissionais permaneçam em formação nos seus cenários de prática, utilizando os seus problemas reais como questões orientadoras da aprendizagem. Estes cursos buscam, também, valorizar o papel do preceptor e modificar seu olhar e atitude diante da preceptoria. Pensar formação em saúde na perspectiva do SUS implica em diversificar os cenários de aprendizagem, privilegiando uma formação baseada nas redes de atenção à saúde, devendo haver uma integração entre serviço e ensino nos espaços de educação e do trabalho em saúde, onde todos os atores têm um papel fundamental.

\section{ABSTRACT \\ The role of the preceptor in professional training in health services}

The study aimed to evaluate the role of the preceptor in the training of dentistry students in the discipline "Supervised Internship in Dentistry" at the Faculty of Dentistry at UFMG. A questionnaire with open and closed questions about the experiences and impressions of students, teachers and tutors from six internship fields located in Belo Horizonte was used. Eleven students, ten preceptors and four professors participated in this study. All students and professors and $50 \%$ of preceptors consider that preceptorship is part of the health professional's attributions. Most actors stated that the health professional feels motivated and prepared to act as a preceptor. All actors considered important the student's participation in internships in health services during professional training and stated that the preceptor knows about the discipline's objectives. Only $20 \%$ of preceptors said they had already participated in a preceptorship training course and $80 \%$ expressed interest in participating. The participants' perception of the role of the preceptor in the training of health professionals was positive. Some preceptors are not aware that preceptorship is part of their role as health professional. Actions that seek to train and make preceptors aware of their role in training future health professionals are needed.

Descriptors: Preceptorship. Unified Health 
System. Delivery of Health Care. Dental Staff.

\section{REFERÊNCIAS}

1. Brasil 1988. Constituição da República Federativa do Brasil. Brasília, DF: Senado; 1988. Cap. II, Seção II, Art. 200.

2. Brasil. Ministério da Educação. Conselho Nacional de Educação. Câmara de Educação Superior. Resolução CNE/CES 3/2021. Dispõe sobre as Diretrizes Curriculares Nacionais do Curso de Graduação em Odontologia e dá outras providências. [Cited July 12, 2021]. Available from: http://portal.mec.gov.br/ index.php?option $=$ com_docman \&view $=\mathrm{d}$ ownload\&alias $=191741$-rces00321\&cate gory_slug=junho2021pdf\&Itemid=30192.

3. Forte FDS, Pessoa TRRF, Freitas CHSM, Pereira CAL, Carvalho Jr PM. Reorientação na formação de cirurgiõesdentistas: o olhar dos preceptores sobre estágios supervisionados no Sistema Único de Saúde (SUS). Interface Comun Saúde Educ. 2015; 19 (Supl 1):831-43.

4. Da Luz GW, Toassi RFC. Percepções sobre o preceptor cirurgião-dentista da Atenção Primária à Saúde no ensino da Odontologia. Rev ABENO. 2016; 16(1):212.

5. Trajman A, Assunção N, Venturi $M$, Tobias D, Toschi W, Brantl V. A preceptoria na rede básica da Secretaria Municipal de Saúde do Rio de Janeiro: opinião dos profissionais de Saúde. Rev Bras Educ Méd. 2009; 33(1):24-32.

6. Brasil. Lei $n^{\circ} 8080 / 90$. Dispõe sobre as condições para a promoção, proteção e recuperação da saúde, a organização e o funcionamento dos serviços correspondentes e dá outras providências. [Cited July 12, 2021]. Available from: https://legislacao.presidencia.gov.br/atos/
?tipo=LEI\&numero $=8080 \&$ ano $=1990 \&$ at o=9f7gXSq1keFpWT905.

7. Finkler M, Caetano JC, Ramos FRS. Integração "ensino-serviço" no processo de mudança na formação profissional de Odontologia. Interface Comun Saúde Educ. 2011; 15(39):1053-67.

8. Bulgarelli AF, Souza KR, Baumgarten A, Souza JM, Rosing CK, Toassi RFC. Formação em saúde com vivência no Sistema Único de Saúde (SUS): percepções dos estudantes do curso de odontologia da Universidade Federal do Rio Grande do Sul (UFRGS), Brasil. Interface Comun Saúde Educ. 2014; 18(49):2014.

9. Oliveira ET, Vasconcelos MVL, Rodarte RS, Esteves RZ. Reflexões sobre a prática pedagógica dos cirurgiões dentistas preceptores de estágio. Atas CIAIQ. 2017; 2:259-69.

10. Barreto VHL, Monteiro ROS, Magalhães GSG, Almeida RCC, Souza LN. Papel do preceptor da atenção primária em saúde na formação da graduação e pós-graduação da Universidade Federal de Pernambuco: um Termo de Referência. Rev Bras Educ Méd. 2011; 35(4):578-83.

11. Leme PAT, Pereira AC, Meneghim MC, Mialhe FL. Perspectivas de graduandos em odontologia acerca das experiências na atenção básica para a sua formação em saúde. Ciênc Saúde Colet. 2015; 20(4):1255-65.

12. Jesus JCM, Ribeiro VMB. Uma avaliação do processo de formação pedagógica de preceptores do internato médico. Rev Bras Educ Méd. 2012; 36(1):153-61.

13. Warmling CM, Rossoni E, Hugo FN, Toassi RFC, Lemos VA, Slavutzki SMB, et al. Estágios curriculares no SUS: experiências da Faculdade de Odontologia 
da UFRGS. Rev ABENO. 2011; 11(2): 63-

70 .

\section{Correspondência para:}

Andréa Clemente Palmier

e-mail: acpalmier90@gmail.com

Faculdade de Odontologia UFMG

Avenida Presidente Antônio Carlos, 6627

Pampulha

31270-901 Belo Horizonte/MG 